\title{
Exploration of Tourism Development in Danjiangkou Reservoir Area under Background of South-to-North Water Transfer
}

\author{
Haobin $\mathrm{Fu}$ \\ Nanyang Institute of Technology, Nanyang Henan, 473000, China
}

Key Words: South-to-North Water Transfer, Danjiangkou Reservoir Area, Tourism development

\begin{abstract}
The development of South-to-North Water Transfer Project not merely promotes the improvement of national economy, but also brings an unprecedented opportunity for tourism projects in Danjiangkou Reservoir area. In the face of this development opportunity, how to greatly improve living standard of people in Danjiangkou Reservoir area without destruction of local natural ecological environment is an issue considered in tourism project of Danjiangkou Reservoir area. For this development background, this paper explores tourism development project of Danjiangkou Reservoir area under the background of South-to-North Water Transfer, in the hope of achieving multi-win of tourism, economy and culture.
\end{abstract}

\section{Introduction}

South-to-North Water Transfer Project as the largest water conservancy project in optimal allocation of water resources arouses people's attention in the world. This project takes the center line as the emphasis and leads water to Tianjin and Beijing through Hubei, Henan and Yangtze River basin. After dam heightening project is implemented smoothly, it brings great development opportunity for economic development of Danjiangkou Reservoir area, and especially for local tourism resources. How to make the best of this development opportunity and develop tourism resources furthest is a problem needing urgent solution.

\section{Principles of tourism project development in Danjiangkou Reservoir area}

\section{Ecological protection principle}

In South-to-North Water Transfer Project, Danjiangkou Reservoir area as the water source place must fully make sure water quality in the reservoir area cannot be polluted. Thus, we should practically protect and recycle natural resources in the reservoir area according to the conditions of local natural resources, make sure there is no negative effect on local water resource and regard harmonious development of economy, society and economy as the development purpose. Secondly, every coin has two sides. During development of the tourism project, we should realize the destruction to local environment and the impacts of household garbage on water resource in the reservoir area after development of the tourism project. Just because of this, we must place economy in toe first place, intensify pollution governance of ecological scenic region in the reservoir area, conducts ecological influence evaluation of various projects in the reservoir area in advance and take precautions in the process of developing tourism resources in the reservoir area.

\section{Principle of economic development promotion}

Since the reservoir area belongs to an old, boundary and poor region in China, with underdeveloped traffic and single industrial structure. Thus, urban and rural differences are very prominent in this area. When it meets the huge development opportunity of South-to-North Water Transfer Project, Danjiangkou Reservoir area should have the courage to break through and finally achieve economic and ecological sustainable development. For the reservoir area, tourism development is the shortcut to reach this goal. Through continuous excavation and integration of local tourism resources, and development of water tourism project, economic development of 
reservoir area will improve greatly. Especially under tourism development environment, ecological agriculture tourism project will greatly narrow urban and rural differences.

\section{Market operation principle}

In the process of tourism project development in the reservoir area, market operation principle must be followed. Firstly, tourism project development should go through market demonstration. Not just should market requirement and tourist commodities be investigated, but also local customer market should be demonstrated. Hence, in the process of tourism project development in the reservoir area, market operation mode must be followed. Secondly, tourism project construction, operation and subsequent management should depend on market rules. Only in this way, tourism project in the reservoir area can operate efficiently.

\section{Principle of simultaneous operation of tourism development and water source project}

Danjiangkou Dam shoulders the heavy task of South-to-North Water Transfer Project. As the bridge connecting tens of millions of people in Beijing, Tianjin and Hebei and the core advantage of this project, Danjiangkou Dam will certainly attract many tourists for visit and investigation. Hence, tourism development project in the reservoir area is bound to be popular. Because of this, we must synchronously carry out tourism development and water source project and achieve harmonious development of economy and ecology in the reservoir area.

\section{general thought on development of tourism project in Danjiangkou Reservoir area}

The reservoir area is rich in tourism resource, with multiple kinds of resources and large potential. Natural landscape is distributed there, and there are also many mountains, karst caves and geological relics etc. After such policies as closing hillsides to facilitate afforestation and returning the grain plots to forestry, forest coverage rate of the reservoir area is increasing year by year. Meanwhile, the reservoir area also has profound cultural accumulation, such as Han River culture, folk culture and Wudang Mountain culture. All these can serve as tourism development projects of the reservoir area.

How to make the best of local tourism resource advantage and develop it to tourism scenic area is a problem needing urgent solution. Hence, we should firmly seize this development opportunity, give full play to landscape and culture advantages of Danjiangkou Reservoir area, regard Wudang Mountain as the development center, integrate local excellent landscape resources, continuously extend tourism industrial chain and make it a first-class tourism place which integrates landscape interaction, sightseeing, vacationing and health keeping. In the face of this development background, we may position the overall development goal: one core, two states, three lines and four themes.

\section{One core}

One core means Wudang Mountain serves as the center of tourism project development. Wudang Mountain is a famous Taoist mountain and scenic spot in China. The advantage of Wudang Mountain is Taoist culture which mainly includes Taoist architecture, martial art, religious rites, music and legend etc. Thus, we should fully highlight architectural features and martial art theme of Wudang Mountain, enhance protection of cultural relics of Wudang Mountain, and improve local brand influence. Wudang Mountain tourism not merely appears in “One River \& Two Mountains” strategy in Hubei Province in the early stage, but also is included in ecological tourist cultural circle of western Hubei later stage. But its tourism resource also has shortcomings. For instance, due to underdeveloped traffic, tourism projects are very scarce. Tourists can only watch TV indoors. In terms of tourism shopping, since there is no local tourism product feature, tourists' buying inclination cannot be motivated. Hence, in future tourism project development, we must bravely break through constraints and develop some tourism projects with strong entertainment and ornamental value in combination of local development features. During development of tourism project, it is required to protect original landscape, strengthen publicity, enrich tourism contents, increase tourists' duration of stay, greatly boost tourists' consumption level and improve local economic benefit. 


\section{Two states}

Tourism as a special life style is also the optimal way to relax oneself. Confucius said that, "wise people like mountain and kind people like water" . To be more specific, generous and humane people will not be impulsive, and their temperament is steady like the mountain. Thus, such people naturally like mountain. Wise people generally have active thinking, so their temperament is bold and unrestrained like water. Such people naturally like water. Based on this sentence, we understand two states. No matter whether you like mountain, water or both, Danjiangkou Reservoir area can meet tourists' demand.

Although mountain and water resources in the reservoir area are very abundant, development time is late. Shiyan tourism starts from Wudang Mountain tourism. There is exquisite scenery in Wudang Mountain. Besides, Taoist architecture is very grand. As early as 1994, Wudang Mountain was listed in World Cultural Heritage List. In 1980, the special road to Wudang Mountain was built by the government. This is the first step of Wudang Mountain tourism. As of today, Wudang Mountain tourism project has become the pillar of reservoir area tourism. The reservoir area will receive one million person-times of tourists annually, which effectively promotes local economic development.

\section{Three lines}

The first line: east line. South direction from Wudang Mountain to Danjiangkou Reservoir area, where water tourism project ismainly developed. So far, the scenic spot centered by Jingle Palace and Danjiang River Dam has formed, which integrates ecology, investigation and development.

The second line: south line. There are land projects along the south line, from Wudang Mountain, Shiyan City to Fangxian County. Along this line, people can visit the modern city, and experience climbing and gorge tourism projects. In addition, tourists can not just visit natural landscape, but also take hot spring bath and eliminate body fatigue along this line.

The third line: west line, from natural landscape, Yunxian County to western Yunxian County. Along this line, land tourism is dominated. But geological and cultural historical tourism resources are dense along this line. Along this line, tourists can experience cultural tourism which integrates relaxation, investigation and sightseeing. It is worth mentioning that tourists can visit Qinglongshan Dinosaur Egg Oryctocoenosis National Geological Park, and feel the magnificent landscape of past Yunyang City and the footprint of Xu Xiangqian, He Long and other revolutionary martyrs.

\section{Four themes}

The first theme: Taoist architecture led by Wudang Mountain. Since there are many well-preserved buildings in the reservoir area, we can fully know materials of ancient architecture. We should utilize this resource to develop tourism project of the reservoir area. Moreover, except Wudang Mountain, Buddhism temple in the suburbs of Shiyan City and Longquan City also own great development significance. At present, Longquan City has been developed to Longquan Temple tourist area.

The second theme: automobile tourism project represented by Dongfeng Automobile. As a famous automobile city, brilliant automobile culture has been fused in Shiyan City in the development and reform process. Professional automobile factories distributed in the city are the local feature. Hence, we can organize tourists to visit automobile assembly plants and see how automobiles are assembled.

The third theme: natural mountain and water landscape represented by water in the reservoir area. The reservoir area was built in 1958 and completed in 1973. After South-to-North Water Transfer Project, the dam was heightened again. At present, the height of dam top can reach $176.6 \mathrm{~m}$. Meanwhile, since natural species are very rich in the reservoir area, with clear air and good water quality, all kinds of fish are natural and wild, so the taste us very fresh and delicious. Tourists can not just visit beautiful scenery, but also taste delicious food.

The fourth theme: geological tourism represented by Qinglongshan Dinosaur Egg Oryctocoenosis National Geological Park in Yunxian County. The geological park covers an area of about $40000 \mathrm{~km}^{2}$, and dinosaur egg fossil is preserved well in the park. People can feel science popularization, entertainment and relaxation. 


\section{Significance of tourism project development in Danjiangkou Reservoir area}

\section{Cultural effect}

Tourism is a kind of cultural activity. The essence of tourism is the attitude of cultural exploration and life enjoying. Culture not just includes folk custom, but also contains nature. In modern social development, if culture pursuit is not involved in the travelling process, such tourism cannot last for a long time. Culture and tourism have very close connection. For example, in the tourism projects in Danjiangkou Reservoir area, Wudang Mountain, Han River, exile and automobile etc. need to be excavated and organized. Currently, we have gradually developed Taoist music, Dinosaur Egg Oryctocoenosis National Geological Park in Yunxian County and other optimized cultural tourism lines which have welcomed by tourists. The development of reservoir area tourism lines with culture can promote the reservoir area to become a real cultural tourism place and boost local culture quality and taste.

\section{Economic effect}

Economic benefit of tourism development can be reflected in ticket proceeds and tourists' series of consuming behaviors in the travelling process. For tourism development project in Danjiangkou Reservoir area, it also owns enormous development potential and the receiving capacity of the scenic spots does not reach saturation. Therefore, we should continue to deeply develop tourism projects and improve local economic benefit. Furthermore, we can launch agricultural eco-tourism, which will greatly boost participation enthusiasm of local citizens and improve local economic level.

\section{Social effect}

Firstly, since the reservoir area is a bound connecting Beijing, Tianjin and Hebei, the exchange between people in the two regions is greatly intensified, and economic reciprocal development is promoted during development of tourism projects in Danjiangkou Reservoir area. Secondly, through regarding the tourism project in the reservoir area as the carrier, we also intensify publicity of South

- North Water Transfer Project construction, and communicate local conditions and customs and historic culture to the people nationwide so that more people can know and understand the reservoir area. Thirdly, since the number of local people in the reservoir area is small, and local economic conditions lag behind, local people mainly live on external migration, which greatly influences local people growth. The development of tourism resources in the reservoir area can greatly relieve this issue. Fourthly, through development of tourism resource in the reservoir area, local industrial structure can be adjusted well; local projects with high consumption and high pollution can be gradually eliminated; finally, Danjiangkou Reservoir area can step to environmental-friendly and sustainable development way.

\section{Conclusion}

In conclusion, under the development background of South - North Water Transfer Project, tourism development project in Danjiangkou Reservoir area is of great significance. But we must follow ecological protection principle, principle of economic development promotion and market operation principle during development of tourism project. We should not blindly pursue economic promotion, but should develop local tourism project, enhance features of local tourism project, take the way of sustainable development and finally achieve multi-win of culture, economy and social effect in Danjiangkou Reservoir area in accordance with natural environmental conditions and four themes.

\section{Acknowledgement}

This paper belongs to science and technology planning project of Henan Province; project title: Study on Cultural Development of Qushou Danjiang Reservoir Scenic Spot in South-to-North Water Transfer Project. No.: 152102310227 


\section{References}

[1] Pan Shidong, Li Hong, On Prospect and Countermeasure of Economic Development of Han River Cultural Tourism - Based on Cultural Tourism Industry in Shiyan City. Journal of Yunyang Normal College, 2014(04).

[2] Yang Xiucui, Yan Peisheng, Study on Deep Tourism Development of Dashanbao Protection Zone. Green Science and Technology, 2014(02).

[3] Li Jihong, Research on Tourism Development of Non-material Cultural Heritage Performance in Hangzhou City. Journal of Jiamusi Education Institute, 2013(11).

[4] Laing Xiaowei, Study on Tourism Development of Historic City. Beijing Planning Review, 2012(02).

[5] Li Jing, Wang Xiulan, Study on Scientific Investigation Tourism Development of Changbaishan Nature Reserve. Journal of Beihua University (Social Science Edition), 2013(02). 